\title{
Study of rheological properties of cakedough from a mixture of wheat and amaranth flour
}

\author{
Ainash Rustemova ${ }^{1, *}$, Nurudin Kydyraliev ${ }^{2}$, Madina Sadigova ${ }^{3}$, and Nurgul Batyrbayeva ${ }^{1}$ \\ ${ }^{1}$ Almaty Technological University, 050012 Almaty, Kazakhstan \\ ${ }^{2}$ Tourism and Hospitality Management Higher School, Kyrgyz-Turkish Manas University, 720038 Bishkek, Kyrgyzstan \\ ${ }^{3}$ Saratov State Agrarian University named after N.I. Vavilov, 410012 Saratov, Russia
}

\begin{abstract}
The paper presents the study of rheological properties of cake dough from composite mixture of wheat and amaranth flour using Mixolab, Alveolab of CHOPIN company (France). It presents the basic parameters of rheological profile of wheat flour of the first grade "Alia" (Tokmak) and composite wheat and amaranth flour, points of index: index of water absorption, index of stability to mixing, index of gluten, index of viscidity, stability of starch oramylolytic index, index of retrogradations of starch.
\end{abstract}

\section{Introduction}

The technology of choux gingerbread places special requirements on raw materials, technological modes and parameters, so it is necessary to fully study the quality of the main raw materials, the influence of additives on rheological properties of semi-finished products.

According to many scientists, the study of rheological properties of doughusing Mixolab device allows estimating the purpose of the studied flour [1].

The purpose of the study is to conduct a comparative assessment of rheological properties of semi-finished products from wheat flour of the first grade "Alia" (Tokmak) and from the composite mixture of wheat flour and amaranth flour.

\section{Materials and methods}

Baker's wheat flour of the first grade "Alia" (Tokmak) according to GOST 26574-2017 was used in the work; amaranth flour as per TU 9293-006-18932477-2004; composite mixture of wheat flour and amaranth flour at a ratio of $85: 15$.

The rheological properties of dough were assessed using the Mixolab devices according to GOST 544982011, ISO 17718-2013, Alveolab according to GOST R 51415-99 ISO 27971 by Chopin Technologies (France).

Based on the analysis of obtained mixograms, the rheological profile was assessed against the following indices: water absorbing capacity; mixing; gluten+; viscosity; amylase; retrogradation.

The falling number was determined using the PCP-7 device according to GOST 30498-97 and ISO 3093-82. Weight fraction and the quality of raw gluten were defined according to GOST 27839-2013.
The damaged starch value was determined using Chopin SD Matic analyzer as per GOST 17715-2015.

Formula, preparation technology of Tykvennye choux gingerbread, quality assessment of products is given in previously published article [2].

\section{Results and discussion}

Quality indices of wheat and composite flour are given in Table 1.

Table 1. Raw material quality indicators

\begin{tabular}{|l|c|c|}
\hline \multicolumn{1}{|c|}{ Indicator } & $\begin{array}{c}\text { Wheat flour of } \\
\text { the first grade } \\
\text { "Alia" } \\
\text { (Tokmak) }\end{array}$ & $\begin{array}{c}\text { composite mixture } \\
\text { of wheat flour and } \\
\text { amaranth flour at a } \\
\text { ratio of 85:15 }\end{array}$ \\
\hline Moisture, \% & 13.4 & 12.7 \\
\hline $\begin{array}{l}\text { Gluten quantity, } \\
\%\end{array}$ & 26.8 & 16.4 \\
\hline $\begin{array}{l}\text { Gluten quality, } \\
\text { FDM }\end{array}$ & 68 & 56 \\
\hline Falling number, $\mathrm{s}$ & 351 & 329 \\
\hline $\begin{array}{l}\text { Damaged starch } \\
\text { value: }\end{array}$ & 22.6 & 20.3 \\
$\begin{array}{l}\text { USD } \\
\text { AACC }\end{array}$ & 6.56 & 4.2 \\
\hline
\end{tabular}

Table 1 Shows that the gluten content of the composite mixture decreased by $38.8 \%$ due to the absence of gluten in the amaranth flour.

As for wheat flour of the first grade "Alia" flour the falling number was $351 \mathrm{~s}$, and for the composite mixture of wheat and amaranth flour $-329 \mathrm{~s}$, since the damaged starch index is lower than the control sample.

Figures 1a, b and Table 2 show the analysis of rheological properties of wheat and composite flour using Mixolab device.

Corresponding author: aist_2707@mail.ru 


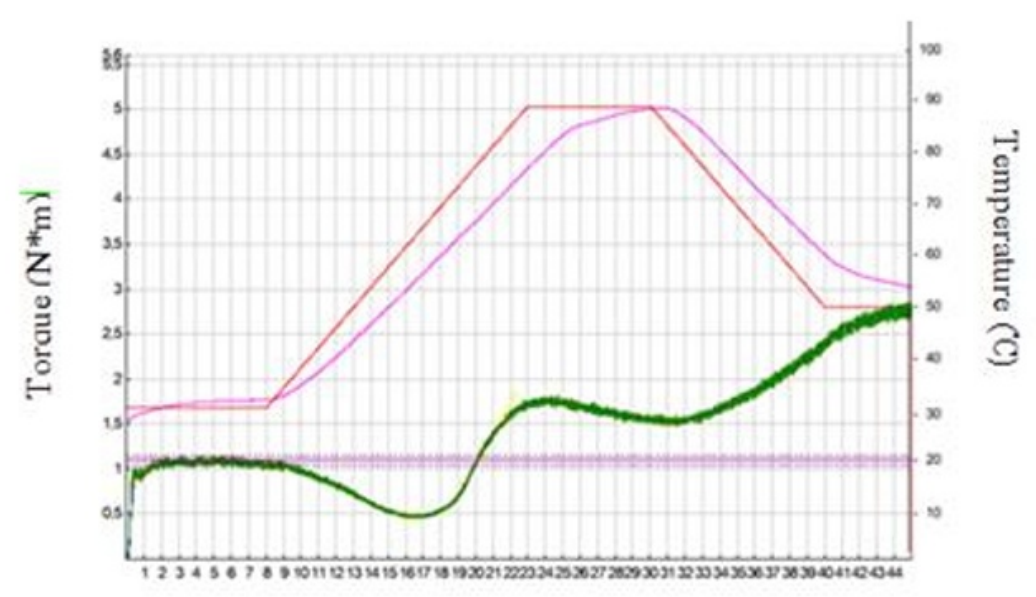

Time $(\mathrm{min})$
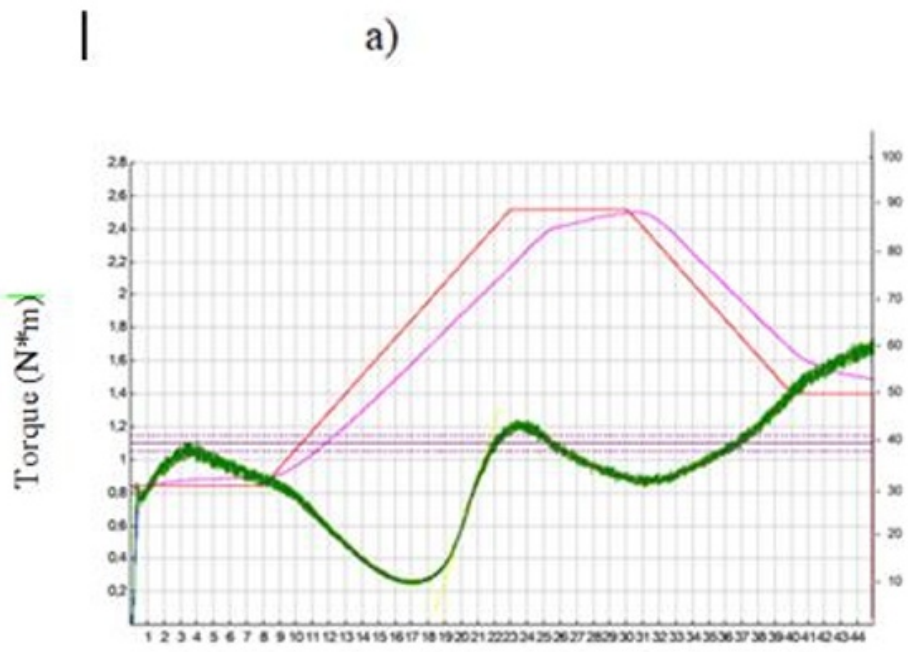

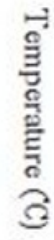

Time (min)

b)

Fig. 1. Rheological profile. Chopin+ protocol for flour ( $a$ - sample of wheat flour of the first grade "Alia"; $b$ - sample of composite mixture of wheat and amaranth flour)

Table 2. Main parameters of the rheological profile and calculated reaction rates of wheat flour of the first grade "Alia" and the composite mixture of wheat and amaranth flour (Chopin+ protocol)

\begin{tabular}{|c|c|c|c|c|c|c|}
\hline \multirow[t]{2}{*}{ Parameter } & \multicolumn{2}{|c|}{ Time, min } & \multicolumn{2}{|c|}{ Torque $\left(\mathrm{N}^{*} \mathrm{~m}\right)$} & \multicolumn{2}{|c|}{$\begin{array}{c}\text { Dough } \\
\text { temperature, }{ }^{\circ} \mathrm{C}\end{array}$} \\
\hline & No. 1 & No. 2 & No. 1 & No. 2 & No. 1 & No. 2 \\
\hline $\mathrm{C} 1$ & 5.15 & 3.48 & 1.088 & 1.057 & 31.3 & 31.2 \\
\hline CS & 8.00 & 8.00 & 1.047 & 0.876 & 31.6 & 31.9 \\
\hline $\mathrm{C} 2$ & 16.33 & 17.02 & 0.475 & 0.256 & 54.4 & 56.5 \\
\hline C3 & 24.42 & 23.70 & 1.762 & 1.207 & 82.4 & 79.9 \\
\hline C4 & 30.98 & 31.20 & 1.532 & 0.867 & 89.6 & 89.1 \\
\hline C5 & 45.02 & 45.00 & 2.768 & 1.685 & 54.1 & 52.9 \\
\hline \multicolumn{7}{|c|}{ Slope ratio, $\mathrm{N} \cdot \mathrm{m} / \mathrm{min}$} \\
\hline No.1 & \multicolumn{2}{|c|}{$\alpha^{*}=-0.088$} & \multicolumn{2}{|c|}{$\beta^{* *}=0.338$} & \multicolumn{2}{|c|}{$\gamma^{* * *}=-0.032$} \\
\hline No. 2 & \multicolumn{2}{|c|}{$\alpha *=-0.096$} & \multicolumn{2}{|c|}{$\beta^{* *}=0.312$} & \multicolumn{2}{|c|}{$\gamma^{* * *}=-0.054$} \\
\hline
\end{tabular}

Note: No. 1 -wheat flour of the first grade "Alia"; No. 2 composite mixture of wheat and amaranth flour; ${ }^{*} \alpha$ - characteristic of liquefaction reaction rate expressed by the tangent angle to a mixolabogram from the moment of reaching $30^{\circ} \mathrm{C}$ to $\mathrm{C} 2$ point; $* * \beta$ - characteristic of starch gelatinization reaction rate expressed by the tangent angle to a mixolabogram withinC2-C $3 ; * * * \gamma-$ characteristic of amylolysis speed expressed by the tangent angle to a mixolabogram within $\mathrm{C} 3-\mathrm{C} 4$.

Index scores determined by Mixolab Profiler: water absorption index - $\left(\mathrm{I}_{1}\right)$, index of stability to mixing $\left(\mathrm{I}_{2}\right)$, gluten+ index $-\left(\mathrm{I}_{3}\right)$, viscosity index (maximum viscosity during heating) - $\left(\mathrm{I}_{4}\right)$, starch stability or amylolytic index $-\left(\mathrm{I}_{5}\right)$, starch retrogradation index $-\left(\mathrm{I}_{6}\right)$ are shown in Table 3.

Figure 2 shows profiles of wheat and composite mixture of wheat and amaranth flour. 
Table 3. MixolabProfiler Index Scores

\begin{tabular}{|c|c|c|c|c|c|c|}
\hline Samples & $\mathrm{I}_{1}$ & $\mathrm{I}_{2}$ & $\mathrm{I}_{3}$ & $\mathrm{I}_{4}$ & $\mathrm{I}_{5}$ & $\mathrm{I}_{6}$ \\
\hline $\begin{array}{c}\text { Wheat flour of the first grade } \\
\text { "Alia" }\end{array}$ & 2 & 7 & 4 & 5 & 6 & 9 \\
\hline $\begin{array}{c}\text { Composite mixture of wheat } \\
\text { and amaranth flour }\end{array}$ & 9 & 3 & 1 & 2 & 3 & 5 \\
\hline
\end{tabular}

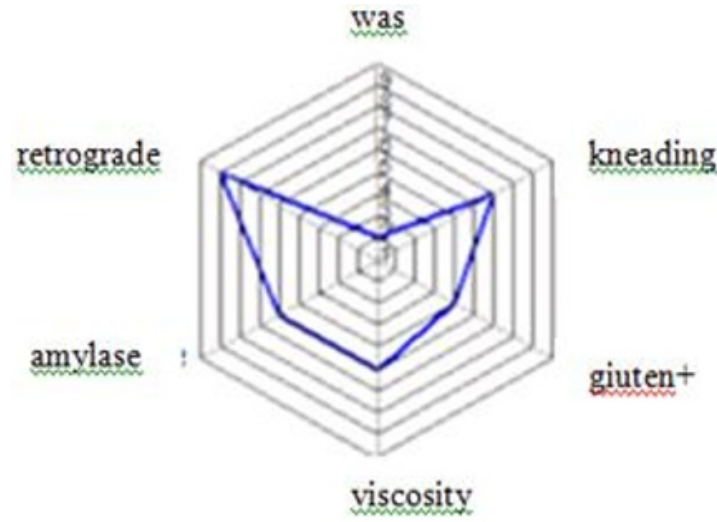

a)

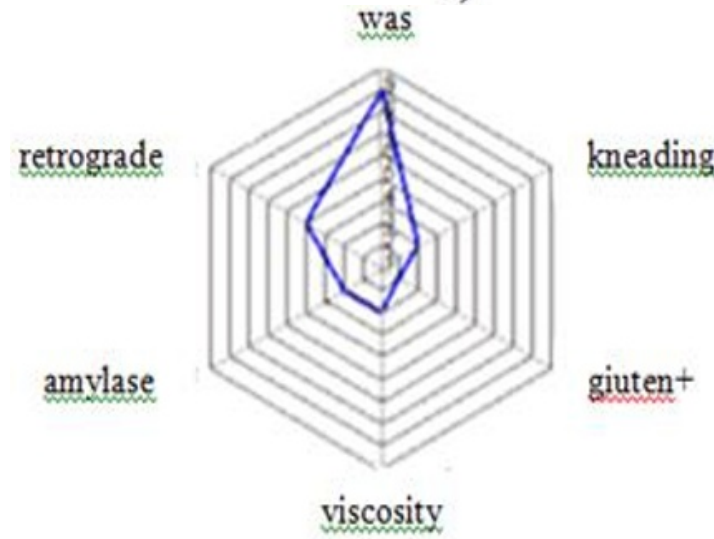

b)

Fig. 2. Mixolab Profiles: a) wheat flour of the first grade "Alia"; b) composite mixture of wheat and amaranth flour

According to the analysis of rheological properties of wheat flour of the first grade "Alia"and the composite mixture of wheat and amaranth flour, it was found that water absorption capacity increased 4.5 times due to the increase in the content of food fibers in the mixture. It is known that water absorption capacity affects the whole process of baking, and is also an important economic indicator that affects the volume yield of finished products.

The mixing time of a dough sample was reduced 2.5 times, the gluten+ index was reduced 4 times. According to Tulyakov D.G. et al. [3], there is no correlation of gluten+ index with gluten quantity and quality indicators, and according to our obtained data, on the contrary, there is direct dependence. The viscosity index is reduced 2.5 times because it depends on the degree of starch damage (Table 1). Therefore, the amylase index is reduced twice. The retrogradation index of a prototype decreased by 4 units, which will increase the storage life of finished products $[4,5]$.

When defining rheological characteristics of dough using Chopin alveolab the following parameters were determined: energy of dough deformation; dough elasticity (P); dough extensibility (L); curve shape index $(\mathrm{P} / \mathrm{L})$; blowing index $(\mathrm{G})$.

The resulting alveograms are shown in Figure $3(a, b)$ and Table 4.

The obtained curves show that the extensibility is reduced 2 times and the elasticity is increased by 44 units under the influence of amaranth flour, so the inflation index decreases (from 17.3 to $12.6 \mathrm{~mm}$ ).

The value of dough deformation energy increases, hence the "flour force" of dough increases.

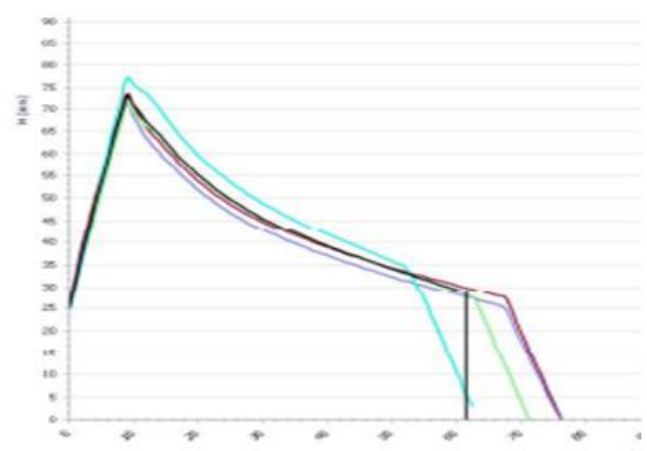

a)

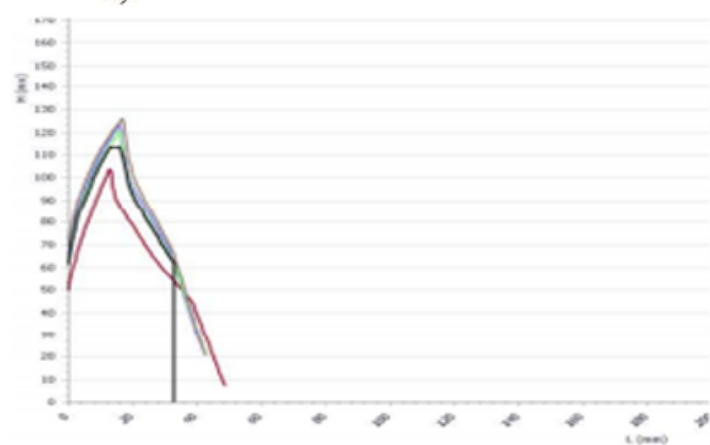

b)

Fig. 3. Alveogram of dough from wheat flour of the first grade "Alia"(a) and alveogram of dough from compositemixture ofwheat flour and amaranth flour

Table 4. Rheological parameters of control and experimental semi-finished product

\begin{tabular}{|l|c|c|}
\hline \multirow{2}{*}{ Indicator } & \multicolumn{2}{|c|}{ Dough samples } \\
\cline { 2 - 3 } & $\begin{array}{c}\text { Wheat } \\
\text { flour of the } \\
\text { first grade } \\
\text { "Alia" }\end{array}$ & $\begin{array}{c}\text { Composite } \\
\text { mixture of } \\
\text { wheat flour and } \\
\text { amaranth flour }\end{array}$ \\
\hline $\begin{array}{l}\text { Energy of dough } \\
\text { deformationW, J }\end{array}$ & $185 \cdot 10^{-4}$ & $194 \cdot 10^{-4}$ \\
\hline $\begin{array}{l}\text { Maximum positive pressure } \\
\text { P, mmwater column }\end{array}$ & 81 & 125 \\
\hline $\begin{array}{l}\text { Mean x-coordinate under } \\
\text { discontinuity L, mm }\end{array}$ & 61 & 32 \\
\hline $\begin{array}{l}\text { Curve shape index P/ L, } \\
\text { mm water column }\end{array}$ & 1.33 & 3.91 \\
\hline Blowing indexG, mm & 17.3 & 12.6 \\
\hline
\end{tabular}


The production of choux gingerbreadreflects the practical application of research results. The results of organoleptic study of ready choux gingerbreadare shown in Figure 4.
The profilogram (Fig. 4) shows better consumer propertiesat $15 \%$ content of amaranth flour in the formula of choux gingerbread.
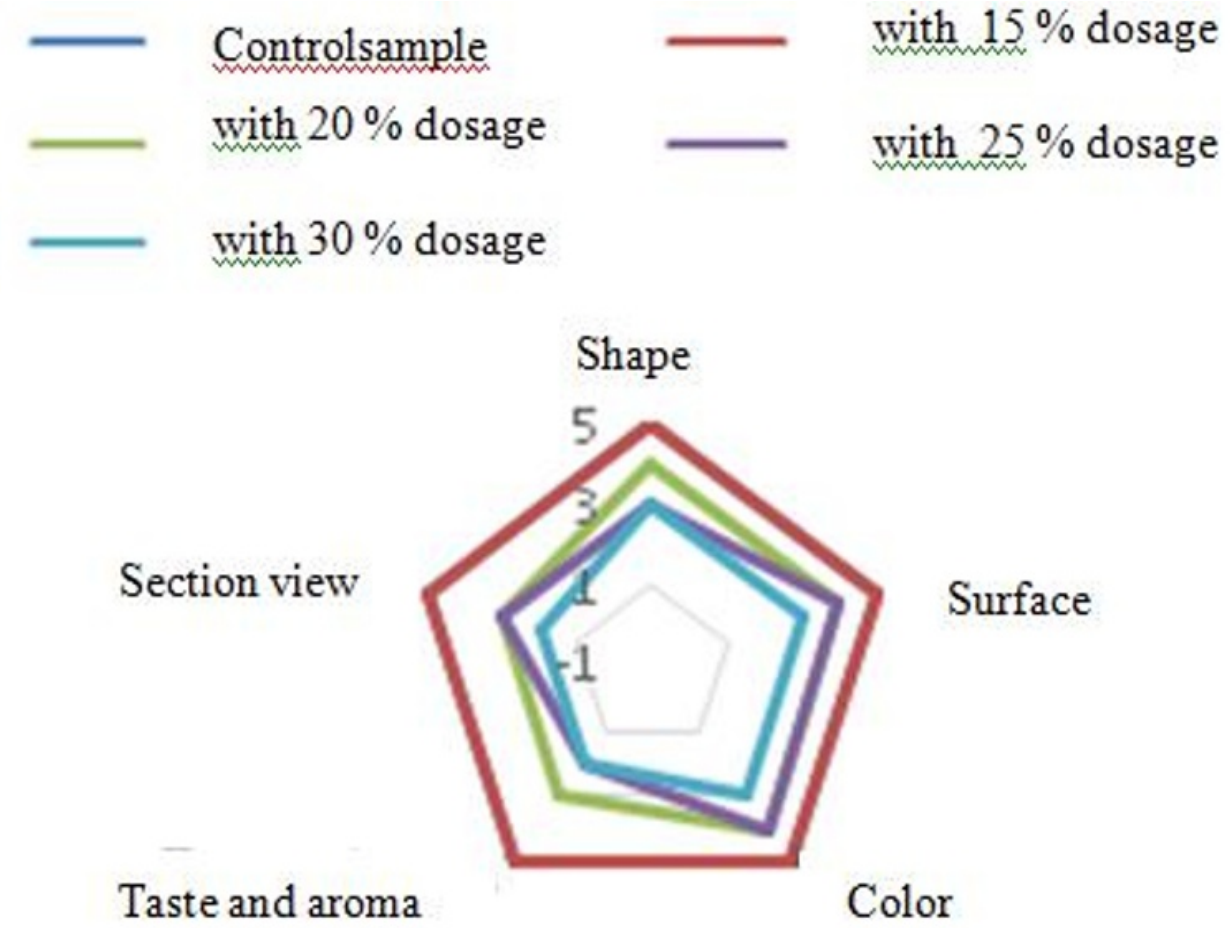

Fig. 4. Profilogram of Tykvennye chouxginger breadwith different amaranth flour content

\section{Conclusion}

The studies made it possible to conclude that when $15 \%$ of amaranth flour was added to the composite mixture, water absorption capacity was increased by 4.5 times. According to alveolab indications, the extensibility of dough is reduced, the elasticity is increased, at the same time the dough mixing time is reduced by 2.5 times, which positively affects the process of dough preparation for choux gingerbreadand allows producing goods with more gentle texture and increased volume. The reduction of the retrograde index of dough sample by 4 units slows hardening of finished products.

Based on the obtained data, we recommend a composite mixture with amaranth flour for the production of flour confectionary products.

\section{References}

1. N.V. Sokol, N.S. Sanzharovskaya, O.P. Khrapko, Theoretical and practical aspects of production of bread of functional purpose (KubSAU, Krasnodar, 2018)

2. A.Zh. Rustemova, Use of non-traditional raw materials in the production of choux gingerbread, Sci., new technol. and innovate. of Kyrgyzstan, 7, 9-13 (2018)

3. D.G. Tulyakov, E.P. Meleshkina, I.S. Vitol, Biochemical and rheological properties in the assessment of different types of flour, Bread products, 6, 30-34 (2017)

4. A. Dyuba, K. Rysev, Modern method of grain and flour quality control according to rheological properties of dough, determined with the help of Mixolab profiler, in Coll. of mater. of the I scientific and pract. Conf. with int. particip. "Management of rheological properties of food products, " 86-95 (Moscow State University of Food Production, Moscow, 2008)

5. GOST ISO 17718-2015. Grain and flour from soft wheat. Determination of rheological properties of dough depending on the conditions of kneading and temperature rise (Standard form, Moscow, 2015) 